\title{
INTEGRASI SISTEM MONITORING BERBASIS MIKROKONTROLLER UNTUK PEMANTAUAN KUALITAS AIR DAN CUACA DI DANAU DENGAN TEKNOLOGI MINIBUOY
}

\author{
INTEGRATION OF MONITORING SYSTEM BASED ON MICROCONTROLLER FOR WATER \\ QUALITY AND WEATHER MONITORING WITH MINIBUOY'S TECHNOLOGY IN LAKE
}

\author{
Dendy Mahabror dan Waryanto \\ Pusat Pengkajian dan Perekayasaan Teknologi Kelautan dan Perikanan \\ Badan Penelitian dan Pengembangan Kelautan Perikanan \\ Jl. Pasir Putih I, Ancol Timur- Jakarta Utara \\ E-mail: mahabror_dee@yahoo.com
}

Diterima tanggal: 4 Maret 2013, diterima setelah perbaikan: 29 April 2013, disetujui tanggal: 1 Agustus 2013

\begin{abstract}
ABSTRAK
Indonesia memiliki banyak danau besar dan kecil. Aktivitas budidaya di danau banyak dilakukan khususnya budidaya ikan air tawar. Proses budidaya air tawar tidak dapat terlepas dari kualitas perairan, rendahnya kualitas perairan menunjukkan adanya polutan sehingga keseimbangan perairan terganggu yang menyebabkan terjadinya gagal panen atau kematian ikan dalam waktu yang singkat. Selain parameter kualitas air, kondisi cuaca juga menjadi faktor pemicu terhadap perubahan kualitas perairan. Pemantauan kualitas perairan dan cuaca secara kontinyu (realtime) sangat dibutuhkan untuk mendeteksi dini jika terjadi perubahan kualitas air secara mendadak. Sistem pemantauan yang cocok untuk digunakan di lingkungan seperti ini adalah autonomous minibuoy technology. Perencanaan desain awal teknologi minibuoy dengan melakukan kajian awal desain struktur dan uji integrasi perangkat sensor dan logger berbasis mikrokontroller tipe AtMega 128 serta dilengkapi perangkat komunikasi data GPRS (General Packet Radio Service) agar dapat beroperasi secara otomatis dan kontinyu. Untuk desain awal struktur minibuoy didapatkan desain yang kecil dan padat dengan berat total termasuk perangkat elektrikal sebesar $60 \mathrm{~kg}$. Uji fungsi sensor dan perangkat elektrikal di lapangan selama 3 jam menghasilkan kemampuan pengukuran dan perekaman yang memiliki tingkat kestabilan dan akurasi yang tinggi.
\end{abstract}

Katakunci: budidaya, minibuoy, GPRS, mikrokontroller

\begin{abstract}
Indonesia has many large and small lakes. Aquaculture activities in the lake is mostly donlfory freshwater fish culture. The process of fresh water aquaculture can not be separated from water quality, poor water quality indicates pollutants into water and cause fist harvest failure or death of fish suddenly. Beside that water quality parameters, weather conditions are also a triggering factor to changes in water quality. Water quality and weather monitoring is needed to detect the change water quality is suddenly with continuasly such as autonomous minibuoy technology. Pre-design Minibuoy technology has a pre-assessment structure design and the integration of microcontroller-based sensor and logger type of ATmega 128 and data communication such as devices equipment GPRS (General Packet Radio Service) to operate automatically and continuously. For the pre-design of the structure has small dimension and compact with a total weight including electrical devices at $60 \mathrm{~kg}$. Test functions of sensors and electrical devices in the field for 3 hours, that's results for measurement and recording have high accuracy and stable.
\end{abstract}

Keywords: aquaculture, minibuoy, GPRS, microcontroller 


\section{PENDAHULUAN}

Proses budidaya ikan di perairan danau air tawar tidak dapat terlepas dari kualitas perairan. Kualitas perairan ini merupakan salah satu faktor penentu keberhasilan terhadap hasil produksi. Parameter perairan yang menjadi acuan meliputi kualitas fisik, biologi dan kimia khususnya untuk penerapan pola perikanan intensif dengan padat tebar tinggi.

Pencemaran yang terjadi di perairan di Danau, merupakan masalah penting yang perlu memperoleh perhatian dari berbagai pihak. Hal ini disebabkan beragamnya sumber pencemar yang masuk dan terakumulasi di danau, antara lain berasal dari kegiatan produktif maupun non produktif di upland (lahan atas) dari permukiman dan dari kegiatan yang berlangsung di badan perairan danau sendiri (Pujiastuti, 2013).

Sistem manajemen budidaya yang baik dengan pengelolaan yang ramah lingkungan merupakan solusi terbaik untuk mencegah terjadinya kegagalan produksi dalam usaha akuakultur. Berdasarkan beberapa penelitian yang pernah dilakukan dalam kaitannya dengan kualitas perairan, parameter-parameter yang cukup berpengaruh terhadap perkembangan ikan budidaya antara lain suhu, salinitas, kecerahan, kekeruhan, derajat keasaman $(\mathrm{pH})$ dan oksigen terlarut. (Monalisa, 2010)

Selain parameter kualitas air, kondisi cuaca juga menjadi faktor pemicu terhadap perubahan kualitas perairan. Perubahan cuaca khususnya terkait peningkatan suhu dapat memicu stratifikasi danau dan cadangan air yang lebih kuat, lebih dini, dan lebih lama, dan jika tidak kembali ke semula maka akan terjadi de-oksigenasi pada lapisan dasar (Komunitas Penyuluh Perikanan KKP, 2011).

Menurut Mulyanto (1992), kebutuhan oksigen mempunyai dua aspek, yaitu kebutuhan lingkungan bagi spesies tertentu dan kebutuhan konsumtif yang tergantung pada keadaan metabolisme ikan. Perbedaan kebutuhan oksigen dalam suatu lingkungan bagi ikan dari spesies tertentu disebabkan oleh adanya perbedaan struktur molekul sel darah ikan yang mempengaruhi hubungan antara tekanan parsial oksigen dalam air dan derajat kejenuhan oksigen dalam sel darah.
Antara oksigen dan temperatur berbanding terbalik, jika temperatur sangat tinggi maka kelarutan oksigen menurun, begitu sebakliknya. Hal ini dikarenakan, temperatur yang tinggi maka terjadi penguapan dipermukaan air, sehinggga kelarutan oksigen menurun.

Bukti pentingnya kesehatan lingkungan untuk mendukung kesinambungan usaha akuakultur dapat terlihat dalam sistem budidaya jaring apung di beberapa waduk seperti Jatiluhur dan Cirata.

Dalam beberapa tahun terakhir ini, berita kematian massal ikan di jaring apung di waduk tersebut hampir selalu terdengar, terutama pada saat musim hujan. Fluktuasi suhu air waduk yang cukup signifikan diduga menyebabkan terjadinya pergerakan massa air dari dasar perairan ke permukaan (up-welling) (Syahailatua, 2008).

Massa air dari lapisan bawah perairan biasanya memiliki kadar oksigen terlarut yang rendah dan kadar polutan (seperti amonia) yang tinggi. Hal inilah yang sering menyebabkan kematian ikan secara mendadak dan massal seperti yang terjadi di waduk Cirata dan Jatiluhur. Proses up-welling terjadi secara alamiah dan tidak selalu merugikan asalkan kondisi dasar perairan tidak terdapat kadar polutan tinggi.

Di beberapa danau/waduk, para pembudidaya ikan memanfaatkannya sebagai lahan budidaya ikan yang menggunakan sistem keramba atau Keramba Jaring Apung (KJA). Sifat perairan danau/waduk yang masih dianggap sebagai common property (milik bersama) dan open access (sifat terbuka) menyebabkan pertumbuhan KJA di berbagai tempat berkembang sangat pesat dan cenderung tidak terkontrol dan tak terkendali. Hal tersebut didukung dengan budidaya ikan berbasis pakan buatan (pelet) dimana aktivitas budidayanya menggunakan pemberian pakan hampir $70 \%$ dari proses produksinya (Azwar et al., 2004).

Pada saat jumlah distribusi pakan melampaui batas tertentu dapat mengakibatkan proses sedimentasi yang tinggi sehingga terjadi penumpukan sisa pakan di dasar perairan. Kejadian ini akan menyebabkan penurunan kualitas perairan (pengurangan pasokan oksigen dan pencemaran air danau/waduk) yang pada akhirnya mempengaruhi ekosistem waduk/danau. 
Berdasarkan dari beberapa kejadian, terindikasi 2 faktor yang merupakan pemicu kematian ikan massal ini yaitu faktor cuaca yang dapat mempengaruhi kondisi kualitas perairan dan sistem manajemen tentang pemanfaatan perairan danau yang melebihi daya dukung lingkungan perairan tersebut.

Melihat proses terjadinya kematian ikan massal di waduk tersebut akibat perubahan kualitas fisikbiokimia perairan yang disebabkan pergantian cuaca dan buruknya kualitas air akibat limbah dari sisa pakan di dasar waduk yang naik kepermukaan, maka diperlukan sebuah sistem pemantauan secara kontinyu dan terkini untuk dapat memberikan early warning terhadap petani budidaya terkait penurunan kualitas perairan.

Sistem pemantauan yang cocok dengan menggunakan autonomous minibuoy technology. Minibuoy adalah sebuah perangkat pengukur parameter perairan seperti kualitas air dan cuaca yang berbentuk pelampung kecil sehingga dapat terapung diatas air. Teknologi seperti ini umumnya dilakukan di laut lepas atau samudera yang sudah banyak diterapkan oleh beberapa instansi luar negeri seperti NOAA-Amerika atau SEAWATCHNorwegia. Parameter yang akan didapat dari sistem yang dibangun meliputi :

1. Arah dan kecepatan angin

2. Suhu udara

3. Tekanan udara

4. Kelembaban udara

5. Curah hujan

6. Ketinggian air/pasang surut

7. Dissolved oxygen (DO)

8. Suhu air

9. $\mathrm{pH}$

10. Salinitas

11. Kekeruhan

Teknologi ini dapat melakukan pengamatan terhadap perubahan cuaca dan kualitas perairan secara otomatis dan real time sehingga mempermudah dalam operasionalisasi pemantauan waduk atau danau.

Tujuan perencanaan perangkat sistem monitoring secara otomatis berbasis mikrokontroller untuk pemantauan lingkungan perairan budidaya perikanan di waduk. dengan pemanfaatan wahana teknologi minibuoy.

Adapun sasaran dari perancangan adalah tersedianya perangkat integrasi perangkat sensor dan logger untuk pemantauan lingkungan perairan budidaya perikanan di waduk secara otomatis dan realtime dengan wahana minibuoy.

Manfaat yang diinginkan adalah terpantaunya kondisi perairan waduk secara cepat, tepat dan kontinyu serta dapat menjadi perangkat early warning system bagi petani budidaya jika terdapat perubahan kualitas perairan secara mendadak. Keluaran dari perancangan ini adalah satu paket desain autonomous minibuoy technology untuk pemantauan kualitas perairan waduk secara mandiri.

\section{BAHAN DAN METODE}

Peralatan yang dibutuhkan untuk desain struktur (minibuoy) dan elektrikal (perangkat keras) antara lain:

a. Komputer dengan processor minimal Pentium 4 dan memory $1 \mathrm{~Gb}$.

b. Multimeter

c. Logic probe

d. Solder, attraktor dan timah

e. Kabel downloader dan kabel serial

f. Adaptor $12 \mathrm{~V}$

g. Osciloscope Tektronik $40 \mathrm{mHz}$

h. Pulse Generator Model GL-3

i. Software pemrograman $\mathrm{C}$ dengan Code Vision AVR C Compiler.

j. Software pro-engineer

Untuk rancang bangun perangkat keras sensor, logger dan sistem power antara lain:

a. Base sensor water pressure

b. Base sensor magnetic anemometer

c. Base sensor potentiometric wind vane

d. Base sensor temperature PT 100

e. Base sensor humidity IC HIH4000

f. Base sensor barometric pressure MPX 5100 AP

g. Base sensor tipping

h. Bucket Radiation Shelter Passive

i. Sensor water quality YSI-6600V2

j. Modul Logger multi channel (analog-digital) compatible Http

k. Modul Memory External R/W with RS232

1. Modem GPRS Fastrack Xtend

m. Panel Surya @ 25Wp Polycristalline sebanyak 2 buah.

n. Control Charge SC $990(12 \mathrm{~V}-10 \mathrm{~A})$

o. Accu 45Ah Maintenance Free 
Penelitian ini merupakan tahap awal untuk perencanaan minibuoy di danau sebagai instrument pengukur kualitas air dan cuaca yang berfungsi sebagai perangkat early warning system terhadap pencemaran atau perubahan kondisi perairan secara ekstrem.

Tahapan dalam proses rancang bangun terbagi menjadi 2 yaitu :
a. Struktur buoy
b. Elektrikal

\section{A. Struktur Buoy}

Untuk langkah awal pembuatan struktur buoy yaitu dengan mendesain rangka dari penempatan instrument-instrumen yang akan digunakan. Setelah semua mekanik instrument yang akan digunakan telah jadi, langkah berikutnya yaitu menghitung berat dari rangka dan instrument tersebut.

Setelah itu mendesain buoy atau wahana terapungnya agar dapat menopang rangka dan instrument tersebut agar tetap stabil apabila diletakkan pada permukaan air, serta dilakukan penataan untuk tempat elektriknya minibuoy. Wahana pelampung ini direncanakan terbuat dari bahan dasar fiber glass yang merupakan bahan dasar dari pembuatan kapal speedboat.

\section{B. Elektrikal}

Penentuan spesifikasi perancangan alat dengan cara menentukan kriteria komponen yang akan dibutuhkan untuk rancang bangun komponen elektrikal. Penggabungan atau integrasi pada teknologi minibuoy meliputi sensor, logger, data communication dan power system dapat dilakukan ujicoba laboratorium dan lapangan. Sistem elektrikal ini akan dirancang secara otomatis sehingga mudah di operasionalkan secara kontinyu di lapangan.

\section{HASIL DAN PEMBAHASAN}

\subsection{Perencanaan Minibuoy}

Satu unit minibuoy yang didesain untuk dapat mengapung diatas permukaan air waduk dengan perencanaan dan perhitungan yang cermat sehingga menjadikan buoy dengan ukuran kecil, ringan dan kedap air.

Mini buoy ini sebagai sarana penyimpan rangkaian elektrikal yang berfungsi melakukan perekaman hasil pengukuran parameter cuaca dan kualitas air yang bekerja secara otomatis, kontinyu dan mandiri tanpa membutuhkan operator.

a. Desain struktur

Tahap pertama yaitu melakukan desain struktur yang berfungsi sebagai penyangga floater/pelampung dan menjadi area tumpuan mooring line. Untuk desain minibuoy ini digunakan software pro-engineer 3D dengan desain terbagi menjadi beberapa bagian.

1. Untuk desain rangka tengah, didapatkan diameter $60 \mathrm{~cm}$ dan tinggi $80 \mathrm{~cm}$. Sisi dalam rangka tengah sebagai wadah peletakkan modul power dan data logger.

2. Untuk desain rangka luar dengan diameter $100 \mathrm{~cm}$ dan tinggi $30 \mathrm{~cm}$. Rangka ini berfungsi sebagai tumpuan flotter.

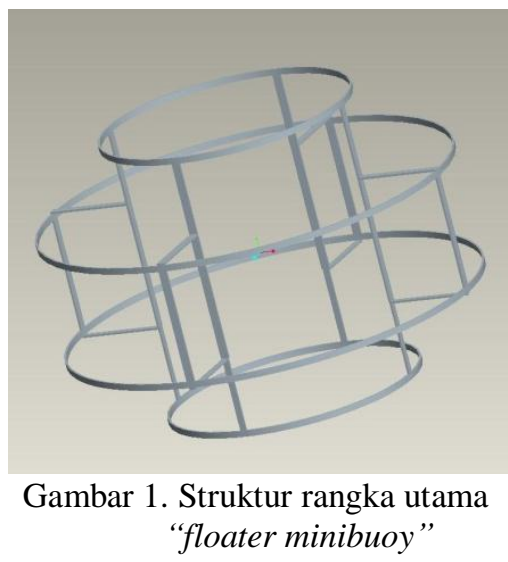

Figure1. Main structure of floater minibuoy

3. Untuk desain rangka atas dengan diameter $120 \mathrm{~cm}$ dan tinggi $50 \mathrm{~cm}$. Rangka ini berfungsi sebagai pelindung floater pada saat deploy buoy dan penopang rangka sensor cuaca.

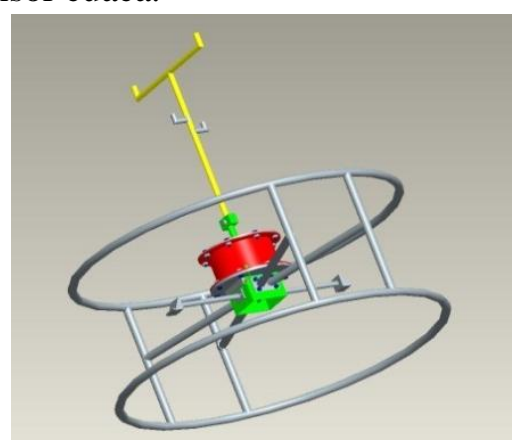

Gambar 2. Struktur rangka pelindung Figure2. Protection structure

b. Desain floater/pelampung

Untuk floater/pelampung mengikuti bentuk struktur dengan ukuran yang sama dan terbuat 
dari bahan Fiberglass dan Polyester Resin dengan ketebalan $\pm 3 \mathrm{~cm}$ sehingga didapatkan volume ruang sebesar $\pm 0,4 \mathrm{~m}^{3}$.

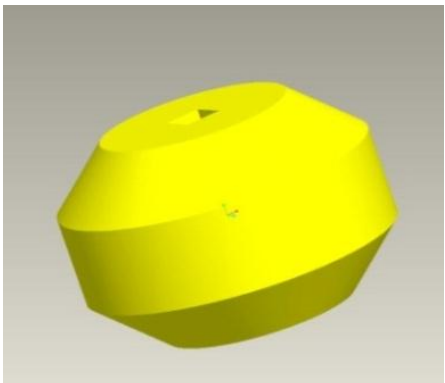

Gambar 3.Desain "floater minibuoy"

Figure3. Design of floater minibuoy

c. Penggabungan rangka dan floater

Tahapan selanjutnya adalah penggabungan desain rangka, floater dan perangkat sensor serta komponen penunjang lainnya sehingga didapatkan estimasi beban keseluruhan yaitu sebesar $\pm 60 \mathrm{~kg}$.

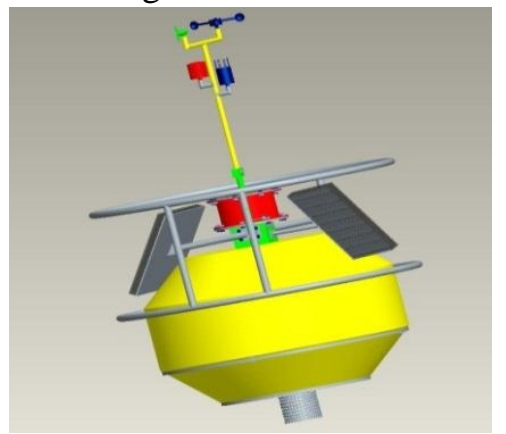

Gambar 4. Desain teknologi minibuoy

Figure 4. Design of technology's minibuoy

\subsection{Perencanaan Perangkat Keras Elektrikal}

Untuk integrasi perangkat sensor, logger, modul telemetri dan sistem power sebagai berikut :

a. Menyusun rangkaian berdasarkan data sheet dan keperluan.

b. Menguji rangkaian menggunakan papan roti sebelum diintegrasikan dalam PCB.

c. Membuat skematik rangkaian menggunakan Altium Protel DXP2004 kemudian mencetak file.pcb menjadi PCB.

d. Menyusun komponen-komponen pada PCB dan proses solder.

e. Menguji masing-masing fungsi kompnen menggunakan multimeter dan logic probe.

f. Melakukan trouble shooting jika didapatkan kesalahan pada jalur rangkaian.

g. Melakukan pemograman mikrokontroller dengan software pemrograman $\mathrm{C}$ dengan Code Vision AVR C Compiler. h. Melakukan uji fungsionalitas mikrokontroller dalam membaca input sensor dan transfer data menuju modem untuk transmit data ke server.

\subsection{Konfigurasi Integrasi Sistem Monitoring.} Desain sistem yang direncanakan untuk sistem monitoring terbagi menjadi beberapa bagian yaitu:

a. Sensor

Sensor merupakan perangkat utama yang berfungsi sebagai media pengukur sehingga menghasilkan sebuah besaran atau nilai.

b. Interface

Interface sendiri diartikan penghubung antara dua sistem atau alat, sebagai media penghubung antara satu subsistem dengan subsistem lainnya. Melalui penghubung ini memungkinkan sumber daya atau materi mengalir dari satu subsistem ke subsistem yang lainnya.

c. Logger

Merupakan perangkat elektrikal yang mencatat data dari dari waktu ke waktu yang berasal dari sensor yang digunakan.

d. Communication Data

Bagian perangkat berupa modem yang berfungsi sebagai media transfer data dari logger menuju web server dengan menggunakan akses jaringan GPRS (General Packet Radio Service).

e. Web Server

Fungsi utama sebuah web server adalah untuk mentransfer berkas atas permintaan pengguna melalui protokol komunikasi yang telah ditentukan.

f. Users

Pengguna yang membutuhkan atau memanfaatkan data dan informasi cuaca dan kualitas air.

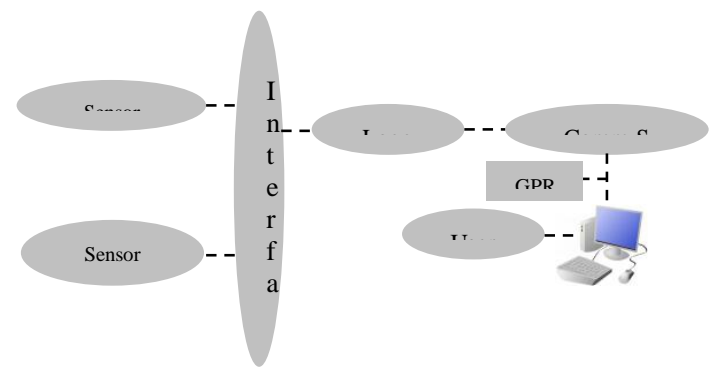

Gambar 5. Konfigurasi sistem monitoring berbasis GPRS

Figure 5. Configuration of monitoring system based on GPRS 
Integrasi perangkat sensor dan logger meliputi beberapa komponen dan tahapan antara lain :

a. Sensor Pasang surut

Sensor pasang surut seri CS-PT 40 merupakan sensor yang mempunyai tingkat kehandalan yang tinggi dan tahan lama, stabil, serta mempunyai tingkat akurasi untuk mengukur kedalaman kolom air.

Tipe sensor yang digunakan untuk pengukuran pasang surut dengan prinsip pressure atau tekanan yaitu sensor dapat membaca tekanan kolom air berdasarkan perbedaan kedalaman. Base sensor yang digunakan berbahan silicon diapragma yang didalamnya terdapat wiring yang bersifat fleksibel berdasarkan tekanan yang diterima. Kemampuan pengukuran maksimal dari sensor ini 5 meter dengan tingkat akurasi $25 \mathrm{~mm}$. Untuk input tegangan yang dibutuhkan 12-30Vdc dengan output signal 4-20 mA dimana keluaran besaran $4 \mathrm{~mA}$ menunjukkan nilai meter dan $20 \mathrm{~mA}$ menunjukkan nilai 5 meter.

b. Sensor Arah Angin

Perangkat lainnya yang digunakan pada sistem ini yaitu penunjuk arah angin atau biasa disebut perangkat wind direction vane. Bentuk sensor penangkap arah angin seperti bagian ekor pesawat, vane ini secara langsung terhubung ke sebuah konduktif potensiometer yang presisi terletak di bagian dalam sensor. Output dari sensor ini berupa tegangan analog yang langsung sebanding dengan arah angin ketika eksitasi tegangan DC secara konstan diterapkan pada potensiometer.

Spesifikasi dari perangkat ini yaitu continuous rotation potentiometric dengan range rotation $360^{\circ}$. Output signal berupa tegangan DC analog dengan tingkat keakurasian $1 \%$.

c. Sensor Kecepatan Angin

Anemometer C3 merupakan versi perbaikan dari desain tiga cangkir populer digunakan dalam penilaian angin selama beberapa dekade, diproduksi dengan standar industri yang tepat. Model C3 rotor terbuat dari polikarbonat berat bagi daya tahan luar biasa dan kehandalan. Model C3 dasar sensor juga terbuat dari polikarbonat kasar, sehingga lebih tahan terhadap kerusakan selama instalasi.
Anemometer ini terdiri dari 3 cup yang berfungsi untuk menangkap hembusan angin yang kemudian akan menghasilkan sinyal listrik yang kemudian dirubah menjadi suatu nilai. Secara prinsip perangkat ini menggunakan generator sistem dimana perputaran cup akan menginduksi gelombang sinus tegangan yang dihubungkan ke coil sehingga menghasilkan sebuah tegangan (V) dengan frekuensi sebanding kecepatan angin.

Perangkat anemometer ini memiliki output linearitas sehingga sensor ini ideal dan mudah dalam melakukan konversi data sampling dari hasil pengukuran. Spesifikasi perangkat ini dapat melakukan pengukuran hingga kecepatan $96 \mathrm{~m} / \mathrm{s}$ dengan tingkat akurasi 0,1 $\mathrm{m} / \mathrm{s}$.

Prinsip kerja dari sensor ini yaitu sinusoidal signal dengan keluaran frekuensi $0 \mathrm{~Hz}-125$ $\mathrm{Hz}$, yang artinya pada kecepatan $0 \mathrm{~m} / \mathrm{s}$ maka frekuensi yang dihasilkan $0 \mathrm{~Hz}$ sedangkan pada kecepatan $96 \mathrm{~m} / \mathrm{s}$ dihasilkan frekuensi sebesar $125 \mathrm{~Hz}$ sehingga perubahan kecepatan angina akan sebanding dengan perubahan frekuensi yang dihasilkan secara linier.

\section{d. Sensor Suhu Udara}

Resistance Temperature Detector (RTD) memiliki prinsip dasar pada tahanan listrik dari logam yang bervariasi sebanding dengan suhu. Kesebandingan variasi ini adalah presisi dengan tingkat konsisten/kestabilan yang tinggi pada pendeteksian tahanan. Platina adalah bahan yang sering digunakan karena memiliki tahanan suhu, kelinearan, stabilitas dan reproduksibilitas.

Platinum Pt 100 pada plant kontrol suhu memiliki fungsi yang hampir sama dengan sensor NTC, dimana letak perbedaannya adalah pada bahan pembuatan sensor. Platinum Pt 100 dibuat dari platinum dengan resistansi nominal 100 pada suhu $0{ }^{\circ} \mathrm{C}$. Prinsip sensor ini berdasarkan besaran hambatan yang diterima pada kondisi tertentu, $100 \mathrm{ohm}$ setara dengan 0 ${ }^{0} \mathrm{C}$ dan 138,4 ohm setara dengan $100{ }^{0} \mathrm{C}$. Kemampuan pengukuran base sensor Pt 100 ini antara $0-125{ }^{\circ} \mathrm{C}$ dengan tingkat akurasi 0,2 $\%$. 
e. Sensor Kelembaban Udara

Sensor kelembaban menggunakan komponen utama IC HIH4000 sebagai sensor kelembaban. Sensor ini mempunyai output yang linier yang memungkinkan untuk dimasukkan secara langsung ke dalam suatu kontroler atau peralatan lain. Arus yang diperlukan sensor ini sangat kecil hanya 200 $\mathrm{mA}$ sehingga cocok untuk aplikasi yang menggunakan baterai dengan daya kecil. Sensor ini tersusun atas beberapa lapis bahan pelindung yang tahan terhadap air, debu, kotoran, minyak, dan bahan sejenisnya.

Sensor Kelembaban HIH-4000 Series dirancang khusus untuk OEM volume tinggi (Original Equipment Produsen). Sensor ini mengeluarkan arus hanya $200 \mathrm{~A}$ dan bervariasi secara linier. HIH-4000 Series sangat cocok untuk tegangan rendah seperti dengan sistem operasi baterai Seri HIH-4000 memiliki kualitas RH (Kelembaban Relatif) cukup baik dengan berbahan polimer termoset kapasitif dengan dilengkapi elemen on-chip terintegrasi pengkondisian sinyal.

Untuk penggabungan sistem antara sensor $\mathrm{RH}$ dengan logger maka diperlukan sirkuit interface seperti gambar diatas, dimana terdapat exciter 5v, IC atau mikrokontroller dan serial TTL converter. Penggunaan exciter $5 \mathrm{v}$ untukmemberikan penguatan daya pada sensor dengan tegangan maksimal 5volt. sebagai pengontrol sistem pada interface berada pada mikrokontroller dimana pengaturan input dan output data diatur sesuai dengan konfigurasi yang diinginkan.

f. Sensor Tekanan Udara

Sensor tekanan, sensor ini memiliki transduser yang mengukur ketegangan kawat, dimana mengubah tegangan mekanis menjadi sinyal listrik. Dasar penginderaannya pada perubahan tahanan pengantar (transduser) yang berubah akibat perubahan panjang dan luas penampangnya. Strain gage adalah sebuah contoh transduser pasif yang mengubah pergeseran mekanis menjadi perubahan tahanan. Sensitivitas sebuah strain gage dijelaskan dengan suatu karakteristik yang disebut factor gage, $\mathrm{K}$, yang didefinisikan sebagai perubahan satuan tahanan dibagi dengan perubahan satuan panjang.
Base sensor tekanan yang digunakan adalah tipe MPX510 dengan silicon shear stress strain gauge. Rentang pengukuran yang dapat dilakukan berkisar 150-1150 mBar dengan input tegangan 5 volt. Output variasi nilai fisika berupa tegangan yang dapat dikonversi $0-5 \mathrm{v}$ olt menjadi nilai dengan satuan mBar, yang artinya dengan variasi tegangan 5 volt setara dengan 1150 mBar. Secara prinsip interface yang digunakan seperti halnya interface sensor suhu udara hanya saja ada sedikit perbedaan dimana interface ini dilengkapi dengan penguat tegangan (voltage amplifier) di 5 volt.

\section{g. Sensor Curah Hujan}

Sensor yang digunakan adalah reed switch yang berupa saklar magnet. Jika magnet menyentuh saklar tersebut maka saklar akan bekerja. Tegangan keluaran dari saklar magnet akan masuk ke kapasitor. Kapasitor ini berfungsi menghilangkan bauncing. Kemudian sinyal akan diteruskan ke dalam mikrokontroler. Mikrokontroler mempunyai arus maksimal untuk arus input.

Pemicu Schmitt (Schmitt Trigger) adalah piranti yang mengubah sinyal masukan sembarang bentuk gelombang menjadi gelolmbang kotak pada isyarat keluarannya. Dalam IC 4093 ini terdapat 4 buah penjungkir pemicu Schmitt. Gerbang mensaklar di berbagai titik untuk isyarat menuju positif dan untuk isyarat menuju negatif. Selisih antara tegangan positif (VN) dan tegangan negatif (VH) ditentukan sebagai tegangan histerisis Dalam IC 74LS14 ini terdapat 6 buah penjungkir pemicu Schmitt. Tegangan ambang atas pada pemicu Schmitt yang terdapat dala IC 74LS14 ini dilambangkan dengan VT+ sebesar 1,6 volt, sedangkan tegangan ambang bawahnya VT- sebesar 0,8 volt.

Mikrokontroler memiliki peran utama dalam sistem ini. Semua aktifitas sistem dikendalikan dengan program yang ada dalam mikrokontroler ini. Jenis mikrokontroler yang digunakan adalah mikrokontroler keluarga AVR yaitu ATMEGA128. Atmega128 memiliki 52 saluran input-output untuk berbagai keperluan (Port A, Port B, Port C, Port D), CPU terdiri 52 buah register, timer/counter dengan mode pembanding 
(compare), unit interupsi internal dan eksternal, port USART untuk komunikasi serial, 8 saluran ADC 10 bit, watchdog timer yang dapat diprogram dengan osilator internal, dan port antarmuka SPI dan tegangan operasi di 4, 5-5,5 volt.

h. Sensor Kualitas Air

Untuk pengukuran kualitas air, sensor yang digunakan adalah Sonde multi sensor dimana dalam satu perangkat dapat melakukan pengukuran seperti suhu, $\mathrm{pH}$, kekeruhan, conductivity dan dissolved oxygen (DO). Sensor YSI 600XLMV2 merupakan sensor yang cocok digunakan untuk monitoring in-situ secara realtime dan jangka panjang. Sensor ini dilengkapi dengan internal memory yang mampu menampung data hingga 150.000, dengan interval tiap jam kapasitas memory bisa mencapai 75 hari.

Pada perancangan sistem ini semua sensor mendaptkan power secara terpusat (external power) yang berasal dari accu 12 volt dengan sumber energi dari photovoltaic @25watt sebanyak 2 buah.

Output data dari sensor YSI 600XLMV2 berupa data digital (ASCII) dengan dilengkapi port communication RS232 dan SDI-12 sebagai jalur mengirim data dari sensor menuju logger.

\section{g. Logger}

Data logger (perekam data) adalah sebuah perangkat elektrikal yang mencatat data dari dari waktu ke waktu yang berasal dari sensor yang digunakan. Logger ini berukuran kecil, bertenaga daya 12 volt, portable, dan dilengkapi dengan mikroprosesor, dan memori internal untuk penyimpanan data. Salah satu manfaat utama menggunakan data logger adalah kemampuan untuk secara otomatis mengumpulkan data pada 24-jam sehari.

Dalam miniatur sistem multi sensor ini, keluaran sinyal hasil pengukuran parameterparameter dari sensor biasanya merupakan sinyal yang masih tercampur dan dipengaruhi oleh noise serta level sinyal keluaran yang dihasilkan masih dalam level yang sangat kecil yang tidak mungkin untuk dapat diolah dalam tahap-tahap berikutnya sehingga membutuhkan rangkaian penyangga (buffer) yang berfungsi untuk menstabilkan perubahan keluaran sekaligus memperkuat sinyal perubahan sensor. Keluaran dari sistem sensor ini kemudian diumpankan ke sistem ADC (Analog to Digital Converter) untuk merubah sinyal analog sensor menjadi sinyal-sinyal dalam bentuk digital yang nantinya akan diolah oleh mikrokontroler.ADC yang digunakan dalam sistem logger merupakan fitur built-in dari mikrokontroler yang digunakan.Adapun karakteristik ADC yang digunakan adalah presisi 8 bit (1024 kemungkinan keluaran), tegangan kerja 2,7 5,5 volt, frekuensi cacah $12.50 \mathrm{KHz}$ dan tipe pencacahan Successive Approximation.

Proses selanjutnya, input data dari berbagai sensor (multi input) menjadi satu input (multiplexer) yang kemudian di proses oleh mikrokontroller ATMEGA 128 dengan dilengkapi RTC (real time clock) untuk pengaturan jalur input dan output data berdasarkan persyaratan atau konfigurasi yang diinginkan, seperti waktu sampling perekaman data atau konfigurasi data yang tersimpan. Selain untuk perekaman data, mikrokontroller berfungsi untuk mengatur atau menseleksi data yang akan di proses lebih lanjut untuk transfer data melalui 2 jalur yaitu frekuensi radio dan GPRS.

Mikrokontroler yang digunakan adalah tipe ATMega128. Ada tiga fungsi utama mikrokontroler dalam sistem yang dibangun yaitu :

- Sebagai ADC yang merupakan fitur built-in dari mikrokontroler,

- Sebagai pengolah sinyal yang telah dibaca oleh ADC, menyusun data tersebut menjadi format data dan pengaturan waktu serta sinkronisasi pengiriman data ke sistem pengirim (transmitter), dan

- Mengirimkan data, menerima respon dari dan ke sistem pengirim melalui jalur RS232.

Karena menggunakan lebih dari satu sensor maka digunakan multiplexer sebagai data selektor yang meneruskan data yang diindera ke pengolah data digital yang dikonversikan terlebih dahulu oleh analog to digital converter (ADC). Data digital hasil konversi selanjutnya diolah oleh mikrokontroler sebagai pusat kendali, dalam hal ini menggunakan mikrokontroler, kemudian data tersebut disimpan sementara di data logger sebelum dikirimkan ke server. 
Desain sistem logger ini menggunakan channel yang terdiri dari 8 channel sensor, 2 channel komunikasi data dan 1 channel untuk memory external. Adapun microcontroller yang digunakan adalah ATMega128 dengan karakteristik :

- Saluran I/O sebanyak 56 buah, yaitu Port A, Port B, Port C, Port D, Port E, Port F dan Port G.

- $\quad$ ADC 1 bit sebanyak 8 saluran.

- 2 buah Timer/Counter 8 bit dan 2 buah Timer/Counter 16 bit.

- Dua buah PWM 8 bit.

- Watchdog Timer dengan osilator internal.

- Internal SRAM sebesar 4 kbyte.

- Memori flash sebesar 128 kBytes.

- Interupsi Eksternal.

- Port antarmuka SPI.

- EEPROM sebesar 4 kbyte.

- Real time counter.

- 2 buah Port USART untuk komunikasi serial.

Mengingat waktu perekaman dalam sistem logger cukup panjang dan menampilkan waktu dan tanggal-stamping mekanisme untuk memastikan bahwa setiap nilai data yang disimpan dikaitkan dengan tanggal dan waktu perolehan. Dengan demikian, sistem logger ini dilengkapi dengan built-in real-time clock.

Unit proses dan kontrol merupakan pusat pengendali kerja sistem, mengunakan IC mikrokontroler ATMEGA, type 128. Untuk aplikasi sistem yang direncanakan, dibentuklah sebuah bus kontrol yang terdiri dari WR, RD, ALE dan EOC pada P1.4. Port digunakan sebagai bus data dua arah untuk seieksi input ADC dan membaca 1 bit data hasil konversi ADC. Seieksi input dan start konversi diiakukan secara simultan dengan perintah menulis. Saat perintah ini dilakukan, pin ALE dinaikan ke logika tinggi dan diturunkan lagi ke logika rendah setelah byte alamat dikeluarkan melalui port 0 .

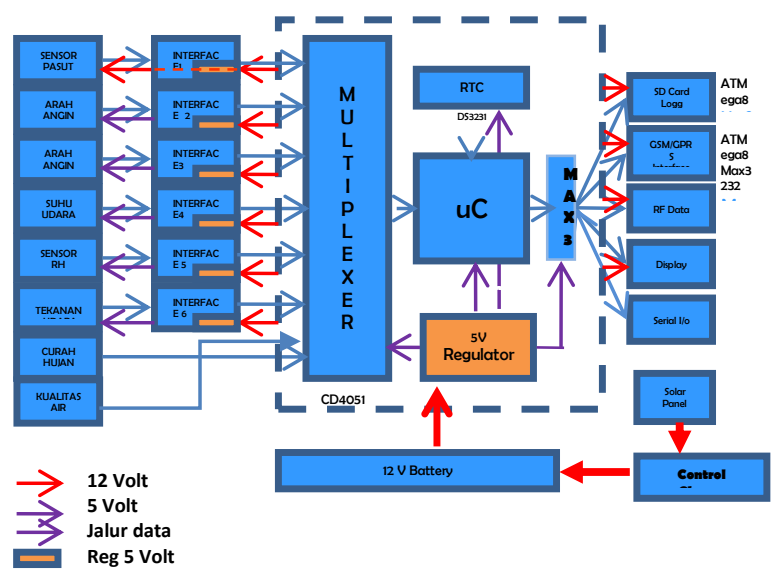

Gambar 6. Konfigurasi Sistem Logger Figure 6. Configuration of Logger System Sumber: Wirawan (2010)

Byte data kemudian dikeluarkan lagi melalui port dan ditahan hingga logika pin kontrol WR, dirubah ke rendah. Keadaan yang hampir sama juga terjadi pada proses pembacaan data, namun pada proses ini logika pin kontrol RD yang disulut ke rendah.

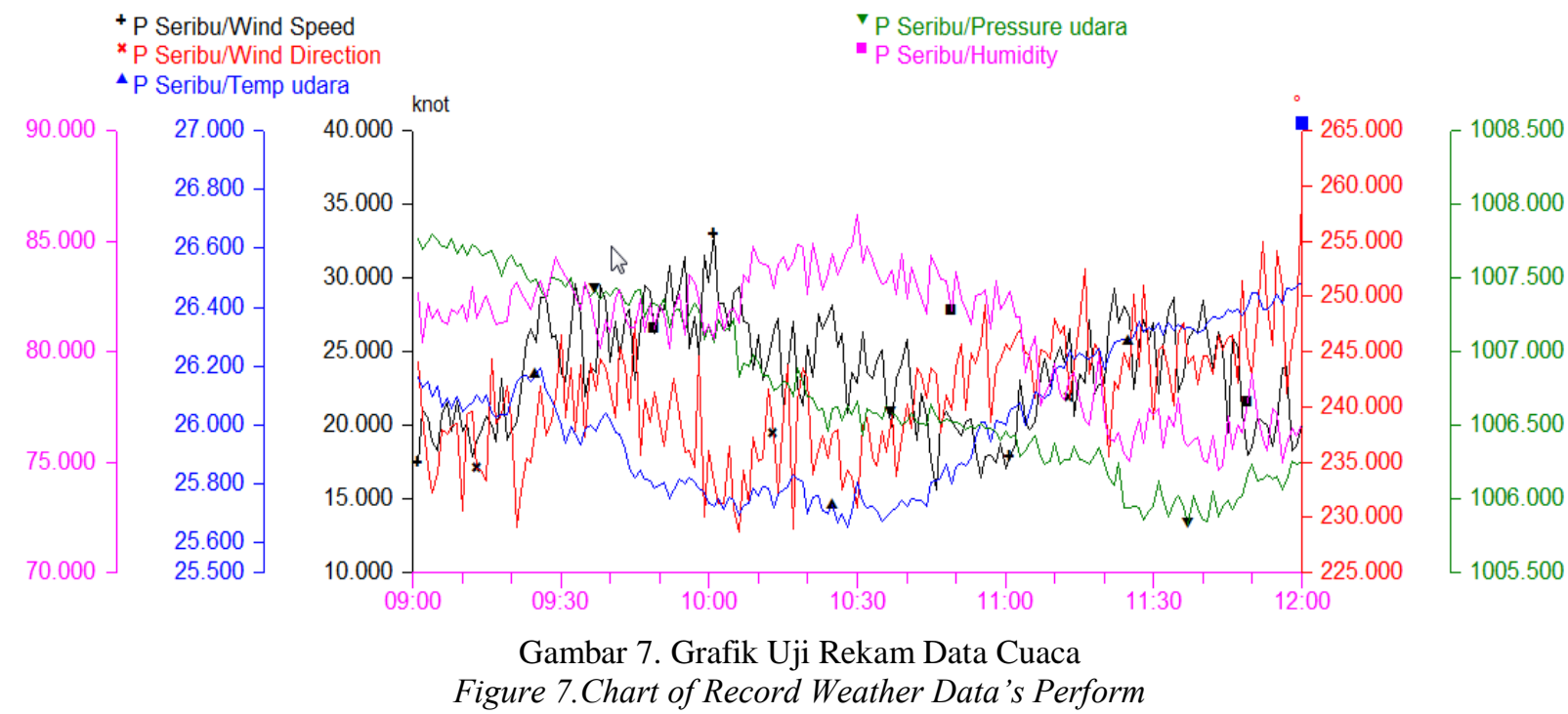




\subsection{Uji Perekaman Data}

Tahap terakhir yaitu melakukan uji kemampuan sensor dalam melakukan pengukuran dan perekaman parameter oseanografi. Uji coba ini dilakukan di Kepulauan Seribu yang meliputi pengukuran cuaca dan kualitas air.

Pengukuran cuaca dengan beberapa parameter meliputi kecepatan angin, arah angin, suhu udara, tekanan udara dan kelembaban udara yang dilakukan selama 3 jam. Dari hasil pengukuran, data relatif stabil tidak terjadi data error (spike data) dan dalam batas pengukuran normal sehingga dapat dikatakan fungsi sensor cuaca berjalan dengan baik dengan hasil rata-rata perekaman data seperti dalam Tabel 1.

Tabel 1. Data rata-rata sensor meteorologi Table 1. Average of meteorology sensor data

\begin{tabular}{lccccc}
\hline Satuan & $\begin{array}{c}\text { Kecepatan } \\
\text { Angin } \\
\text { (knot) }\end{array}$ & $\begin{array}{c}\text { Arah } \\
\text { Angin }\end{array}$ & $\begin{array}{c}\text { Suhu } \\
\text { Udara }\end{array}$ & Tekanan & Kelembaban \\
\hline Min & 17.0 & 228 & 25.7 & 1005.8 & 76 \\
\hline Max & 33.0 & 256 & 26.5 & 1007.7 & 85 \\
\hline Mean & 23.4 & 239 & 26.0 & 1006.7 & 81 \\
\hline
\end{tabular}

Selain tidak ada data error, range hasil pengukuran juga dalam kategori normal, data suhu udara pada jam 09.00-12.00 berada pada kisaran $25,6-26,2{ }^{\circ} \mathrm{C}$. Kondisi kelembaban udara di waktu yang sama berkisar 75 - $85 \%$ dimana kondisi antara suhu udara dan kelembaban berbanding terbalik, suhu rendah $\left(25,6{ }^{\circ} \mathrm{C}\right)$ memiliki kadar kelembaban $(85$ $\%)$ begitu juga sebaliknya. Melihat hasil rekam ini menunjukkan bahwa sensor dapat bekerja dengan baik.

Dari data di atas jika dibandingkan dengan karakteristik kondisi meteorologi Kepulauan Seribu dimana pada Bulan Desember-Maret, kecepatan angin berkisar 7 - 20 knot dengan arah angin dominan dari barat yang dipengaruhi oleh Monsun (Sprintall, 2006 dalam Lubis, 2012). Untuk kondisi suhu udara berkisar $26{ }^{\circ} \mathrm{C}$ dan kelembaban udara $81 \%$, hasil pengukuran ini sesuai dengan observasi BMKG pada 2011 dimana diperoleh suhu udara di Kepulauan Seribu bagian tengah berkisar $26-38{ }^{\circ} \mathrm{C}$ dengan kelembaban \pm $80 \%$ (BMKG, 2011 dalam Lubis, 2012).

Suhu udara rata-rata antara $26,5-28.5{ }^{\circ} \mathrm{C}$ dengan suhu udara maksimum tahunan $29,5-32.9{ }^{\circ} \mathrm{C}$ dan minimum $23,0-23,8{ }^{0} \mathrm{C}$. Kelembaban nisbi ratarata berkisar antara 75 - $99 \%$, serta tekanan udara rata-rata antara 1009,0 -1011,0 mb.

Kelembaban udara juga merupakan salah satu unsur yang mempengaruhi kondisi/keadaan cuaca dan iklim di suatu wilayah tertentu. Secara ilmiah, kelembaban merupakan jumlah kandungan uap air yang terkandung dalam massa udara pada suatu saat (waktu) dan wilayah (tempat) tertentu. Suhu udara adalah ukuran energy kinetik rata - rata dari pergerakan molekul-molekul. Suhu suatu benda ialah keadaan yang menentukan kemampuan benda tersebut, untuk memindahkan (transfer) panas ke benda- benda lain atau menerima panas dari bendabenda lain tersebut. Suhu dan kelembaban udara sangat erat hubungannya, karena jika kelembaban udara berubah, maka suhu juga akan berubah. (Lakitan, 1994)

Untuk pengukuran kualitas air, lama pengukuran bersamaan dengan pengukuran cuaca yaitu sejak pukul 09.00 - 12.00 WIB dengan data yang dihasilkan cukup stabil dan normal sesuai dengan kondisi lingkungan perairan. Salah satu hasil pengukuran kualitas air seperti suhu air, dimana kondisi suhu air semakin meningkat dari jam 09.00 - 12.00 dengan interval $28,5{ }^{\circ} \mathrm{C}-28,65{ }^{\circ} \mathrm{C}$, selain itu parameter oseanografi yang tidak mudah berubah adalah conductivity dimana nilai di lokasi ujicoba berkisar 49,5.

Tabel 2. Data rata-rata sensor kualitas air TablE 2. Average of water quality data's sensor

\begin{tabular}{lccccc}
\hline Satuan & Do & $\begin{array}{c}\text { Suhu } \\
\text { Air }\end{array}$ & Kekeruhan & pH & Konduktivitas \\
& $\mathrm{mg} / \mathrm{l}$ & ${ }^{\circ} \mathrm{C}$ & $\mathrm{ntu}$ & & \\
\hline Min & 5.8 & 28.5 & 50000 & 8.11 & 49.5 \\
\hline Max & 6.4 & 28.7 & 91000 & 8.15 & 49.5 \\
\hline Mean & 6.0 & 28.5 & 65756 & 8.13 & 49.5 \\
\hline
\end{tabular}

Berdasarkan dari hasil perekaman di lapangan jika dibandingkan dengan beberapa penelitian yang sudah pernah dilakukan seperti oleh Sachoemar (2008) yang didapatkan nilai DO berkisar 4,4hingga 7,2 mg/l untuk di perairan Kepulauan Seribu. Untuk suhu permukaan di Kepulauan Seribu pada musim Barat berkisar antara 28,5 $30,0{ }^{\circ} \mathrm{C}$ dan pada musim Timur permukaan antara $28.5-31,0{ }^{\circ} \mathrm{C}$ sedangkan untuk kadar $\mathrm{pH}$ berkisar 7,3 hingga 8,3 . 


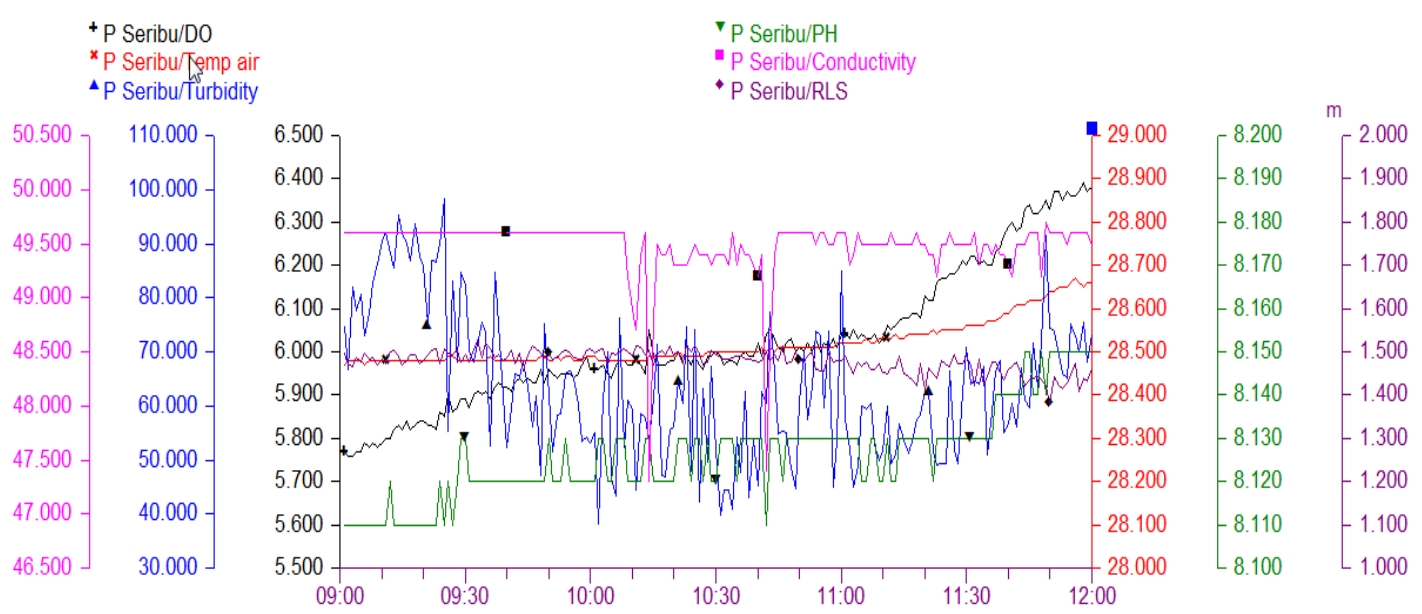

Gambar 8. Grafik uji rekam data kualitas air

Figure 7.Chart of record weather data's perform

Sumber penelitian yang lain juga menyebutkan bahwa suhu muka laut rata-rata di sekitar Teluk Jakarta yang meliputi Kepulauan Seribu berkisar $27,1-29,7{ }^{0} \mathrm{C}$ dengan nilai ekstrim terendah $26,5^{\circ} \mathrm{C}$ dan tertinggi $30,5{ }^{\circ} \mathrm{C}$ (Ilahude, 1980). Sedangkan nilai $\mathrm{pH}$ di Teluk Jakarta dan sekitarnya berkisar 7,9 - 8,2 di lepas pantai, yang merupakan kisaran normal. Dari dua perbandingan data diatas menunjukkan bahwa kinerja sensor dan sistem berfungsi secara baik dan akurat.

\section{KESIMPULAN DAN SARAN}

Berdasarkan hasil rancang bangun integrasi sensor cuaca dan kualitas air, maka dapat diperoleh beberapa kesimpulan antara lain:

1. Desain awal struktur buoy rangka luar dengan diameter $100 \mathrm{~cm}$ dan tinggi $30 \mathrm{~cm}$ dengan berat total platform dan perangkat elektrikal sebesar $60 \mathrm{~kg}$.

2. Untuk floater/pelampung mengikuti bentuk struktur dengan ukuran yang sama dan terbuat dari bahan Fibreglass dan Polyester Resin dengan ketebalan $\pm 3 \mathrm{~cm}$ sehingga didapatkan volume ruang sebesar $\pm 0,4 \mathrm{~m}^{3}$.

3. Uji fungsi sensor kualitas air dan cuaca cukup baik dimana nilai hasil pengukuran sesuai dengan kondisi lapangan dan tidak ada data error selama pengujian.

4. Pengembangan minibuoy berbasis telemetry system dapat dikembangkan sebagai sistem peringatan dini secara realtime bagi pembudidaya KJA di perairan danau atau waduk.

\section{DAFTAR PUSTAKA}

Azwar et al. 2004. Pengaruh pakan ikan terhadap kualitas air danau. Retrieved from www.djpb.kkp.go.id.

Boyes, Walt. 2010. Instrumentation reference book (ed). Butterworth-Heinemann.

Garcier, M. Carrilo. 2009. Autonomous meteorological buoy. Universitat Politècnica de Catalunya, Department of Electronic Engineering.

Ilahude, A.G., dan S. Liasaputra. 1980. Sebaran Normal Parameter Hidrologi di Teluk Jakarta. Dalam : Teluk Jakarta, Pengkajian Fisika, Kimia, Biologi, dan Geologi (A. Nontji dan A. Djamali eds.). LON-LIPI. Jakarta.

Lakitan, B. 1994. Dasar klimatologi.

Lubis, Atika, dan Mira Yosi. 2012. Kondisi meteorologi maritim dan oseanografi di perairan sekitar Pulau Kotok, Kepulauan Seribu: April 2011. Jurnal Ilmu dan Teknologi Kelautan Tropis 4(1): 24-34.

MAX232 transceiver. www.datasheetcatalog.com.

Pujiastuti, P., B. Ismail, dan Pranoto. 2013. Kualitas dan beban pencemaran perairan waduk Gajah Mungkur. Jurnal EKOSAINS, 5(1): 59-75.

Rahmat, Ayi. 2009. Implementasi sistem pemantauan kualitas air dan kondisi ekstrim pada budidaya ikan nila, Buku 5. Prosiding Seminar Hasil Penelitian IPB. 
Rangan, C.S., G.R. Sarma, dan V.S. Mani. 1983. Instrumentation: devices and systems. Tata McGraw-Hill, New Delhi.

Sachoemar, S.I. 2008. Karakteristik Lingkungan Perairan Kepulauan Seribu. Jurnal Air Indonesia, 4(2): 109-114.

Swami, A., Q. Zhao, Y.W. Hong, and L. Tong. (Eds.). 2007. Wireless Sensor Networks: Signal Processing and Communications. John Wiley \& Sons.

Syahailatua, Augy. 2008. Dampak Perubahan Iklim Terhadap Perikanan. Oseana, Vol XXXIII (2): 25-32.

Tjahjono, Anang. 2010. Rancang Bangun Sistem Monitoring dan Kendali Kualitas Air Sungai Secara Online. Jurnal Teknologi dan Lingkungan ITS.

Wavecom modem GSM.www.wavecom.com.

Webster, J. G., and H. Eren. (Eds.). 2014. Measurement, instrumentation, and sensors handbook: Spatial, mechanical, thermal, and radiation measurement (vol. 1). CRC press.

Wirawan. 2010. Komunikasi Pribadi. LAPAN. 